\title{
The Influence of Organizational Culture, Competence and Motivation toward the Quality of Education Services in State High Schools in West Java Province
}

\author{
Ratna Wati (Correspondence Author) \\ Department of Education, West Java Province, Indonesia \\ Ermaya Suradinata \\ Institut Pemerintahan Dalam Negeri \\ Dedeh Maryani \\ Institut Pemerintahan Dalam Negeri
}

Widodo Sigit Pudjianto

Institut Pemerintahan Dalam Negeri

Received: Sep. 13, $2021 \quad$ Accepted: Oct. 13, $2021 \quad$ Online published: Nov. 19, 2021

doi:10.5296/jpag.v11i4.19004ＵRL: https://doi.org/10.5296/jpag.v11i4.19004

\begin{abstract}
The phenomenon that is used as the object of research is the Quality of Education Services at State Senior High Schools in West Java Province. The research objectives are (1) to discuss the influence of organizational culture toward the quality of education services; (2) Discussing the influence of competence toward the quality of education services; (3) Discussing the influence of motivation toward the quality of education services; (4) Get a new concept from discussing the influence of Organizational Culture toward the Quality of Educational Services; (5) Get a new concept from the discussion of the influence of Competence toward the Quality of Education Services; (6) Get a new concept from the discussion of the influence of motivation toward the quality of education services. The research sample of 381 respondents was taken from a population of 54,150 people with the Krejcie sampling technique. Determination of 10 Research Informants using snow ball
\end{abstract}


technique. Collecting data using Literature Study, Questionnaire, Interview and Observation. The data analysis technique used SEM Analysis and Descriptive Analysis which was developed using Observer Triangulation and ASOCA methods. The following research results:

The magnitude of the influence of Organizational Culture toward the Quality of Education Services at State Senior High Schools in West Java Province reached 0.69, which is quite strong and significant. The magnitude of the influence of Competence toward the Quality of Education Services at State Senior High Schools in West Java Province reached 0.55, which is quite strong and significant. The magnitude of the influence of motivation toward the quality of education services at public high schools in West Java province reached 0.86, which is very strong and significant.

The new concepts that can be compiled from the discussion of the influence of Organizational Culture, Competence and Motivation toward the Quality of Education Services at State Senior High Schools in West Java Province are (1) a new concept of School Organizational Patterns; (2) a new concept on the Characteristics of Responses of Education Providers and (3) a new concept on the Drive for Achievement.

Keywords: Organizational Culture, Competence, Motivation and Quality of Education Services

\section{Introduction}

The education development policy in West Java Province includes five pillars of education, namely Increasing the availability of education services; Expanding the affordability of education services; Improving the quality and relevance of educational services; realizing equality in obtaining educational services; and Ensure certainty of obtaining educational services. Among the five pillars of development in the education sector, there are three pillars of education development that are very much needed by the community. The three pillars of education development in question are (1) increasing the availability of educational services; (2) expansion of affordability of education services; and (3) improving the quality and relevance of educational services (Bradley, 1997).

From the 2018/2019 fiscal year to the 2019-2020 fiscal year in West Java, there was only an increase in the number of State Senior High Schools by 6 schools, namely from 501 to 507 schools for 18 Regency Regions and 9 City Regions. In the same period, the increase in the number of private high schools reached 42 schools, from 1,114 to 1,156 schools. Thus, it was revealed that the addition of the number of public high schools was not optimal to implement the three pillars of education development. This means that the quality of education services at public high schools is also not optimal in implementing policies to increase the availability of educational services; policies for expanding the affordability of education services; and policies to improve the quality and relevance of educational services,

The not yet optimal quality of secondary education services in West Java Province appears to be a public service phenomenon that cannot be separated from the influence of various variables. Among the many variables that correlate and influence the quality of educational 
services, a basic assumption arises that Organizational Culture, Competence and Motivation are three variables that have a significant effect on the Quality of Educational Services (Arif $\&$ Maksum, 2017). Assumptions are based on the following major premises:

Organizational culture that is internalized and actualized into a value system of beliefs, norms and ethics of individual behavior, group behavior and organizational behavior of SMA Negeri in providing educational services is a dynamic condition of the organization of the service provider. Therefore, conditionally and functionally Organizational Culture affects the Quality of Educational Services.

Competencies that are formed from intellectual capacity, quality of mental attitude and social integrity in carrying out the teaching profession and educational staff in State Senior High Schools are the abilities and personalities of education staff in carrying out educational functions. Therefore, conditionally and functionally competence affects the quality of education services.

Motivation that is formed from the encouragement of certain desires and or expectations of a person in working or carrying out tasks at a public high school is an individual's internal factor that directs his attitudes and behavior in working or carrying out his profession as an educator or education staff. Therefore, conditionally and functionally motivation affects the quality of education services.

\section{Theoretical Framework}

The theoretical framework consists of the grand theory of Government Science; middle range theory Public Service Management Theory; applied theory Organizational Culture Theory, Competency Theory, Motivation Theory, Public Service Quality Theory. The applied theory that is used as the driven theory for constructing the research variables is as follows:

Organizational culture is shaped by the interaction of four main factors: the personal and professional characteristics of people within the organization, organizational ethics, the nature of the employment relationship, and the design of its organizational structures. Based on this theory, a conceptual definition of the variable is drawn up; conceptual definition is reduced to 4 dimensions of analysis; Dimensions were reduced to 12 manifest variables to be used as 12 research questionnaire items (Boyne et al., 2004).

Spencer and Spencer (1993:9) which show five characteristics of competence which include Motives, Traits, Self-concept, Knowledge and Skill. Based on this theory, a conceptual definition of the variable is drawn up; conceptual definition is reduced to 5 dimensions of analysis; Dimensions are reduced to 15 manifest variables to be used as 15 research questionnaire items

McClelland in Thoha says that there are three human needs, namely, the need for achievement, the need for affiliation, and the need for power. Based on this theory, a conceptual definition of the variable is drawn up; conceptual definition is reduced to 3 dimensions of analysis; dimensions were reduced to 12 manifest variables to be used as 11 research questionnaire items (Thoha, 2006). 
Zeithaml et. al. said: We identified ten general criteria or dimensions and labeled them tangibles, reliability, responsiveness, competence, courtesy, credibility, security, access, communication, and understanding the customer (Zeithaml et al., 1990). Based on this theory, conceptual definitions of variables were compiled; conceptual definition is reduced to 10 dimensions of analysis; dimensions were reduced to 30 manifest variables to be used as 30 research questionnaire items.

\section{Method}

The research combines the quantitative research paradigm and the qualitative research paradigm. The study used dominant les dominant design: QUAL + Qual (D.J creswell, 2009) with the following research techniques:

First, quantitative research was carried out by distributing questionnaires arranged according to a Likert scale. Questionnaires were given to 381 respondents taken from a population of 54,150 people using the Krejcie Sampling Technique. The results of the questionnaire distribution were processed by SEM analysis to obtain the results of the Second Confirmatory Factor Analysis (CFA). Based on the results of the CFA, an Interview Guide was developed to carry out qualitative research (Santoso, 2007).

Second, qualitative research was carried out using Interview Guidelines to deepen the study of the results of the CFA. Interview guidelines were submitted to 10 research informants who were determined by the snow ball technique. The results of the interviews were discussed using Descriptive Analysis which was developed according to the Observer Triangulation (Neumann, 2006) and ASOCA (Suradinata, 2013a)analysis methods.

\section{Result and Discussion}

\subsection{Quantitative Research Results}

The results of quantitative research using Structural Equation Models Analysis (SEM Analysis) are as follows:

4.1.1 Results of Measuring the Influence of Organizational Culture on the Quality of Education Services Pelayanan

Based on the results of the measurement of the path coefficient, it can be seen that the magnitude of the influence of Organizational Culture ( $\left.\xi_{1}\right)$ toward the Quality of Education Services at State Senior High Schools $(\eta)$ in West Java Province reaches 0.69, which is fairly strong. and significant (Ghozali, 2008; Santoso, 2007). The magnitude of the influence of Organizational Culture toward the Quality of Education Services at the State Senior High School is determined by 12 manifest variables. The existence of such an influence shows that between the Organizational Culture of Public Senior High Schools and the Quality of Educational Services there is a meaningful causal relationship: if the Organizational Culture of State Senior High Schools is improved or increased, stimulantly the increase in Organizational Culture is followed by an increase in the Quality of Education Services (Sheng, 2006). Therefore, improving the quality of education services at public high schools in West Java province can be increased by increasing the 12 manifest variables of SMA 
Negeri Organizational Culture. The twelve manifest variables of the SMA Negeri Organizational Culture are as follows: (1) Work view, (2) Work attitude, (3) Work behavior, (4) Ethics of education staff, (5) Ethics of educators, (6) Ethics of students , (7) Relationship between education staff and educators, (8) Relations between educators, (9) Relations between educators and students, (10) Authority, (11) Division of duties, (12) Job description (Thoha, 2006).

4.1.2 Results of Measuring the Influence of Competence on the Quality of Education Services

Based on the measurement results of the path coefficient, it can be seen that the magnitude of the influence of Competence ( $\left.\boldsymbol{\xi}_{2}\right)$ toward the Quality of Education Services at State Senior High Schools $(\eta)$ in West Java Province reaches 0.55, which is quite strong and significant (Yun, 2006). The magnitude of the influence of Competence toward the Quality of Education Services at the State Senior High School is determined by 15 manifest variables. The existence of such an influence indicates that there is a significant causal relationship between competence and quality of education services: if the competence of public high school administrators is increased or increased, the stimulant increase in competence is followed by an increase in the quality of education services. Therefore, improving the quality of education services at public high schools in West Java province can be improved by increasing the 15 manifest variables of the competence of public high school administrators. The fifteen manifest variables of the SMA Negeri Organizational Culture are as follows: (1) Serving Motive, (2) Serving Motive, (3) Achievement Motive, (4) Adaptive, (5) Responsive, (6) Cooperative, (7) Appearance, (8) Attitude, (9) Behavior, (10) general knowledge, (11) Special Knowledge, (12) Social Knowledge, (13) Administrative Skills, (14) Technical Skills, (15) Social Skills.

\subsubsection{Results of Measuring the Influence of Motivation on the Quality of Education Services}

Based on the measurement results of the path coefficient, it can be seen that the magnitude of the influence of Motivation ( $\xi 3)$ toward the Quality of Education Services at State Senior High Schools $(\eta)$ in West Java Province reaches 0.86 , which is very strong and significant. The magnitude of the influence of motivation toward the quality of education services in SMA Negeri is determined by 12 manifest variables. The existence of such an influence indicates that there is a causal relationship between motivation and quality of education services, which means that if the motivation of public high school administrators is increased or increased, stimulantly the increase in motivation is followed by an increase in the quality of education services Therefore, improving the quality of education services at public high schools in West Java province can be improved by increasing the 12 manifest variables of motivation for state high school administrators. The twelve manifest variables of the motivation of SMA Negeri organizers are as follows: (1) Adaptation Needs, (2) Innovation Needs, (3) Creative Needs, (4) Achievement Needs, (5) Communication Needs, (6) Coordination Needs, ( 7) Collaboration Needs, (8) Participation Needs, (9) Needs To Be Recognized, (10) Needs To Be Respected, (11) Needs To Influence, (12) Needs To Master.

From the Second Confirmatory Factors Analysis on the three exogenous latent variables, it is 
known that the Organizational Structure Dimension which is structured on the Organizational Culture variable, the Traits Dimension which is structured on the Competence variable, and the Need For Achiement Dimension which is structured on the Motivation variable are the three most dominant factors contributing to the correlation in the process. the formation of the magnitude of the influence of the exogenous latent variable on the endogenous latent variable. These three dimensions are used as the basis for the preparation of Interview Guidelines for carrying out qualitative research, and the basis for the preparation of New Concepts.

\subsection{Qualitative Research Results}

Based on the analysis of the results of interviews with 10 research informants obtained practical implications from the dimensions of descriptive analysis. The practical implications of the exciological approach are as follows:

\subsubsection{Dimensional Analysis of Organizational Structure}

From the descriptive analysis of various information obtained from research informants, and by using the ASOCA analysis approach, the practical implications of the authority included in the Organizational Structure are one of the dimensions of the Organizational Culture of SMA Negeri. The practical implications in question are as follows:

First, the principal's authority, the implementation of the principal's authority, the principal's ideas and policies must be based on his ability to lead and manage the school. Leading a school means being able to influence, regulate, direct and control individual behavior, group behavior and school organizational behavior. Managing a school means being able to influence, regulate, direct and control managerial activities which include planning, organizing, implementing, reporting and evaluating (Kerlinger, 2006). With such abilities, strengthening and increasing the effectiveness of the implementation of the functions of the School Organizational Structure in order to realize a modern and professional Public High School Organizational Culture.

Second, such abilities are raised by the strength (strength) of school resources which include human resources (man), school financing resources (money), school infrastructure resources (materials), school regulatory resources (method), resources school information technology resources (machines), and school social resources (market). With such strength, strengthening and increasing the effectiveness of the implementation of the functions of the School Organizational Structure in order to realize a modern and optimal Public High School Organizational Culture.

Third, these abilities and strengths are then directed to achieve Opportunities (opportunities) in the school's internal environment and the school's external environment in order to improve performance and achieve various intellectual achievements. With these abilities, strengths and opportunities, various strategic steps have been taken to streamline the implementation of the Organizational Structure function in order to realize a modern and national-standard SMA Organizational Culture. 
Fourth, these abilities, strengths and opportunities are then developed into school culture values. The cultural values in question include beliefs, norms and school ethics in implementing various policies and teaching and learning activities in schools. These values are institutionalized to optimize the implementation of the functions of the Organizational Structure in order to create a modern, professional and national-standard Organizational Culture for Public High Schools.

Fifth, with abilities, strengths, opportunities and culture, various efforts were made to reorient schools to make SMA Negeri as an institution for the development of Agility (intelligence) of the young generation that can be relied upon to prepare the nation's future leaders. In time, these abilities, strengths, opportunities, culture and agility (ASOCA) (Suradinata, 2013b) need to be institutionalized to optimize the implementation of the functions of the school Organizational Structure in order to create a modern, professional, national-standard, and reliable Public High School Organizational Culture to prepare the nation's future leaders.

From the descriptive analysis of various information obtained from research informants, and by using the ASOCA analysis approach, the practical implications of the division of tasks (Suradinata, 2013a) included in the Organizational Structure are one of the dimensions of the Organizational Culture of SMA Negeri. The practical implications in question are as follows:

First, the division of tasks regulated by the Principal or Deputy Principal to Teachers and Administrative Staff must be based on an analysis of the suitability of the Ability (ability) of each teacher or staff with the field of assignment. This division of tasks means that the pattern of school organization must be based on the principle of the right man on the right place; and the pattern of placement of teachers or staff with a like or dislike attitude must be avoided. In addition, the career path of each teacher and/or staff also needs proper attention. Based on the suitability of abilities with the assignment of each teacher or staff, it certainly forms a stronger work motivation to improve individual performance and collective performance. This increase in work motivation and performance is needed to increase the effectiveness of the implementation of the functions of the School Organizational Structure in order to realize a productive, innovative and creative working culture of teachers and staff at SMA Negeri.

Second, such abilities are raised by Strenght (strength) a conducive work environment for the development of the spirit of togetherness and cooperation of teachers and staff in carrying out their duties. The implementation of tasks is carried out by strengthening effective communication and work coordination. With such strength, an increase in the effectiveness of the implementation of the functions of the School Organizational Structure is made in order to realize a communicative, coordinative, and cooperative work culture of SMA Negeri.

Third, these abilities and strengths are then directed to achieve Opportunities (opportunities) in the school's internal environment and the school's external environment in order to improve the quality of educational services and achieve various work achievements. With these abilities, strengths and opportunities, various strategic steps are also carried out to streamline the implementation of the Organizational Structure function in order to realize a Public High School Work Culture that ensures the quality of education services. 
Fourth, these abilities, strengths and opportunities are then developed into school culture values. The cultural values in question include beliefs, norms and school ethics in implementing various policies and teaching and learning activities in schools. These values are institutionalized to optimize the implementation of the Organizational Structure function in order to create a Public High School Work Culture that ensures the effectiveness of the implementation of the educational function.

Fifth, with abilities, strengths, opportunities and culture, various efforts were made to reorient schools to make SMA Negeri as an institution for the development of Agility (intelligence) of the young generation that can be relied upon to prepare the nation's future leaders. In time, these abilities, strengths, opportunities, culture and agility (ASOCA) need to be institutionalized to optimize the implementation of the school's organizational structure functions in order to create a modern, professional, national-standard working culture for public high schools, and ensure the effectiveness of the implementation of the education function to prepare future leaders. in front of a nation that is honest, trustworthy and reliable.

From the descriptive analysis of various information obtained from research informants, and by using the ASOCA analysis approach, the practical implications of the Job Description included in the Organizational Structure are one of the dimensions of the Organizational Culture of SMA Negeri (Ghozali, 2004). The practical implications in question are as follows:

First, the job descriptions arranged according to the job structure and the division of tasks for each position in the school must be based on an analysis of the suitability of the abilities of each teacher or staff with the scope of work. These job descriptions are job descriptions that must show clarity in detail the duties and functions of each position as well as the scope of responsibility of each position in carrying out work or activities. In addition, the job description of each teacher and/or staff also needs to be clarified again with the importance of implementing the communication, coordination and consultation functions for each position in carrying out work or activities. Based on the suitability of the abilities of each teacher or staff with the scope of their work, of course there will be a work process and individual work results as well as effective and efficient work processes and collective work results. Effective and efficient intertwining of work processes and work results is needed to improve the effectiveness of the implementation of the functions of the School Organizational Structure in order to realize a clear, easy and smooth working culture of teachers and staff at public high schools.

Second, such abilities are raised by Strenght (strength) a conducive work environment for the development of a spirit of togetherness and cooperation of teachers and staff who help and strengthen each other with effective communication and work coordination. With such strength, an increase in the effectiveness of the implementation of the functions of the School Organization Structure is made in order to realize an effective, efficient and accountable Public High School Work Culture.

Third, these abilities and strengths are then directed to achieve Opportunities (opportunities) in the internal school environment and the external school environment in order to improve 
the quality of education services that support the implementation of an effective national education system. With these abilities, strengths and opportunities, various strategic steps were also carried out to streamline the implementation of the Organizational Structure function in order to realize a Public High School Work Culture that ensures the effectiveness of teaching and learning activities in schools.

Fourth, these abilities, strengths and opportunities are then developed into school culture values. The cultural values in question include beliefs, norms and school ethics in implementing various policies and teaching and learning activities in schools. These values are institutionalized to optimize the implementation of the functions of the Organizational Structure in order to realize a Public High School Work Culture that supports the implementation of an effective national education system.

Fifth, with abilities, strengths, opportunities and culture, various efforts were made to reorient schools to make SMA Negeri as an institution for the development of Agility (intelligence) of the young generation that can be relied upon to prepare the nation's future leaders. In time, these abilities, strengths, opportunities, culture and agility (ASOCA) need to be institutionalized to optimize the implementation of the school's organizational structure functions in order to create a modern, professional, national-standard working culture for public high schools, and support the effectiveness of the implementation of the national education system to prepare leaders. the future of the nation that is honest, trustworthy and reliable in formulating and implementing various national development policies.

\subsubsection{Traits Dimensional Analysis}

From the descriptive analysis of various information obtained from research informants, and by using the ASOCA analysis approach, the adaptive practical implications included in Traits are one of the dimensions of Competence for State Senior High School administrators. The practical implications in question are as follows:

First, the adaptive ability of all education personnel and students must be based on the ability to understand the threat of the COVID-19 pandemic and its impact on health, individuals, families and communities as well as the impact on the economy and also on education. Adaptive abilities in the school environment are not only useful for anticipating the threat of the COVID-19 pandemic on health; but at the same time it is also useful to innovate in carrying out teaching and learning activities in schools. Thus, adaptive abilities have formed new awareness, new habits and new enthusiasm among education providers and students. This adaptive ability turns out not only to provide a strong motivation to survive; but at the same time provide a strong impetus to innovate and be creative. With their adaptive abilities, education providers and students will certainly continue to strive to carry out educational functions with appropriate methods and media during the COVID-19 pandemic. Adaptive ability inherent in individual behavior and collective behavior is one of the dimensions of the competence of school administrators. This adaptive ability is needed to carry out teaching and learning activities during the COVID-19 pandemic. Although faced with limited resources and distance of activities, with adaptive capabilities, the function of education and teaching and learning activities in State Senior High Schools is still carried out. 
Second, such abilities should be raised with the Strength (strength) of a conducive work environment for the development of a spirit of togetherness and cooperation of teachers and staff who help and strengthen each other with effective communication and work coordination. With such strength, it is necessary to strengthen the competence of education personnel in accordance with the demands and challenges of education during the COVID-19 pandemic, so that the educational performance of public high schools can still meet the needs and expectations of students.

Third, these abilities and strengths are then directed to achieve opportunities that allow or trigger the development of educational methods and media that are useful for improving the quality of educational services. The quality of education services is one of the factors supporting the implementation of an effective national education system. With these abilities, strengths and opportunities, various strategic steps have also been taken to optimize the performance of school services so that the performance of teachers and staff of public high schools is realized which ensures the effectiveness of teaching and learning activities in schools.

Fourth, these abilities, strengths and opportunities are then developed into school culture values. The cultural values in question include beliefs, norms and school ethics in implementing various policies and teaching and learning activities in schools. These values are institutionalized to optimize the competence of school administration so that a competent State High School Learning Culture can be realized to support the implementation of an effective national education system.

Fifth, with abilities, strengths, opportunities and culture, various efforts were made to reorient schools to make SMA Negeri as an institution for the development of Agility (intelligence) of the young generation that can be relied upon to prepare future leaders of the nation. In time, these abilities, strengths, opportunities, culture and agility (ASOCA) need to be institutionalized as well to optimize the implementation of the education function in schools in order to realize a modern, professional, national standard high school learning competency, and support the effectiveness of the implementation of the national education system to prepare future leaders of the nation who are honest, trustworthy and reliable in formulating and or implementing various government administration and management policies.

From the descriptive analysis of various information obtained from research informants, and by using the ASOCA analysis approach, the practical implications of responsiveness are obtained which are included in Traits and become one of the dimensions of Competence for State Senior High School administrators. The practical implications in question are as follows:

First, the responsiveness of all education staff and students must be based on the ability to understand the threat of the COVID-19 pandemic and its impact on health and its consequences on the economy as well as on education. Responsive ability in the school environment is not only useful for anticipating the threat of the COVID-19 pandemic on health; but at the same time it is also useful to innovate in carrying out Distance Learning activities. Thus, responsive ability has formed new awareness, new habits and new 
enthusiasm among education providers and students. This responsive ability turns out not only to provide a strong motivation to survive; but at the same time provide a strong impetus to innovate and be creative. With their responsive capabilities, education providers and students will certainly continue to strive to carry out educational functions with appropriate methods and media during the COVID-19 pandemic. Responsive ability inherent in individual behavior and collective behavior is one of the dimensions of the competence of school administrators. This responsive ability is very much needed to carry out distance learning activities during the covid-19 pandemic. Although faced with limited resources and distance of activities, with responsive capabilities, the function of education and distance learning activities in public high schools is still carried out.

Second, such abilities should be raised with the Strength (strength) of a conducive work environment for the development of a spirit of togetherness and cooperation of teachers and staff who help and strengthen each other with effective communication and work coordination. With such strength, the strengthening of the competence of educational staff is carried out in accordance with the demands and challenges of education during the COVID-19 pandemic, so that the performance of education services at State High Schools is in accordance with the needs and expectations of students during the Covid-19 pandemic

Third, these abilities and strengths are then directed to seize opportunities that enable or trigger the development of more useful educational methods and media to improve the quality of educational services. The quality of education services is one of the factors supporting the implementation of an effective national education system. With these abilities, strengths and opportunities, various strategic steps were also taken to optimize the performance of school services in order to realize the togetherness and cooperation of teachers and staff to ensure the effectiveness of Distance Learning activities in State Senior High Schools.

Fourth, these abilities, strengths and opportunities are then developed into school culture values. The cultural values in question include beliefs, norms and school ethics in implementing various policies and teaching and learning activities in schools. These values are institutionalized to optimize the competence of school administration in order to create a Distance Learning Culture in State Senior High Schools that continues to support the effective implementation of the national education system during the COVID-19 pandemic.

Fifth, with abilities, strengths, opportunities and culture, various efforts were made to reorient schools to make SMA Negeri as an institution for the development of Agility (intelligence) of the young generation that can be relied upon to prepare future leaders of the nation. In time, these abilities, strengths, opportunities, culture and agility (ASOCA) need to be institutionalized as well as to optimize the implementation of the education function in schools in order to realize a modern, professional, national standard high school learning competency, and support the effectiveness of the implementation of the national education system to prepare future leaders of the nation who are honest, trustworthy and reliable in formulating and or implementing various development policies to improve the nation's economy. 


\section{Ml Macrothink}

Journal of Public Administration and Governance

ISSN 2161-7104

2021, Vol. 11, No. 4

From the descriptive analysis of various information obtained from research informants, and by using the ASOCA analysis approach, the practical implications of the cooperative ability are included in Traits which is one of the dimensions of Competence for State Senior High School administrators. The practical implications in question are as follows:

First, the cooperative ability of education staff and students should be based on the ability to understand the adaptation of new habits to anticipate the threat of the COVID-19 pandemic and its impact on health, individuals, families and communities as well as its consequences on education. The cooperative ability of education staff and students is not only useful for anticipating the threat of the COVID-19 pandemic on health; but at the same time it is also useful for developing distance learning collaborations. Thus, cooperative abilities have fostered new awareness, new habits and new enthusiasm among education providers and students. This cooperative ability turns out not only to provide a strong motivation to survive; but at the same time provide a strong impetus to innovate and be creative. With their cooperative abilities, education providers and students will certainly continue to strive to carry out educational functions with appropriate methods and media during the COVID-19 pandemic. Cooperative ability inherent in individual behavior and collective behavior is one of the dimensions of the competence of school administrators. This cooperative ability is very much needed to carry out Distance Learning during the covid-19 pandemic. Although faced with limited resources and distance of activities, with cooperative abilities, the implementation of the educational function through distance learning activities in public high schools can still meet the learning needs of students.

Second, such cooperative abilities should be provided with a Strenght (strength) a conducive work environment for the development of a spirit of togetherness and cooperation of teachers and staff who help and strengthen each other with effective communication and work coordination. With such strength, the strengthening of the competence of educational staff is carried out in accordance with the demands and challenges of education during the COVID-19 pandemic, so that the performance of educational services in public high schools can still meet the learning needs of students.

Third, these abilities and strengths are then directed to achieve opportunities that enable or trigger the development of educational methods and media that are useful for improving the quality of educational services. The quality of education services is one of the factors supporting the implementation of an effective national education system. With these abilities, strengths and opportunities, various strategic steps have been taken to optimize the quality of education services that ensure the effectiveness of Distance Learning in State Senior High Schools.

Fourth, these abilities, strengths and opportunities are then developed into school culture values. The cultural values in question include beliefs, norms and school ethics in implementing various policies and teaching and learning activities in schools. These values are institutionalized to optimize the competence of school administration in order to create a Distance Learning Culture in SMA Negeri that supports the implementation of an effective national education system. 
Fifth, with abilities, strengths, opportunities and culture, various efforts were made to reorient schools to make SMA Negeri as an institution for the development of Agility (intelligence) of the young generation that can be relied upon to prepare future leaders of the nation. In time, these abilities, strengths, opportunities, culture and agility (ASOCA) need to be institutionalized as well as to optimize the implementation of the education function in schools in order to realize a modern, professional, national standard high school learning competency, and support the effectiveness of the implementation of the national education system to prepare future leaders of the nation who are honest, trustworthy and reliable in formulating and or implementing various public service policies to improve the welfare of the community.

\subsubsection{Need For Achievement Dimensional Analysis}

From the descriptive analysis of various information obtained from research informants, and by using the ASOCA analysis approach, the practical implications of adapting needs included in Need For Achiement are one of the dimensions of motivation for state high school administrators. The practical implications in question are as follows:

First, the need to adapt education staff and students should be based on the ability to understand the adaptation of new habits to anticipate the threat of the COVID-19 pandemic and its impact on health, individuals, families and communities and their consequences on education. The need to adapt education personnel and students not only motivates the implementation of health protocols; but at the same time it also motivates the development of distance learning cooperation. Thus, the need to adapt has created new awareness, new habits and new enthusiasm among education providers and students. This need to adapt does not only provide a strong motivation to survive; but at the same time provide a strong impetus to innovate and be creative. With their adaptability needs, education providers and students will certainly continue to strive to carry out educational functions with appropriate methods and media during the COVID-19 pandemic. The need to adapt which is the internal drive of individuals and collective behavior is one of the dimensions of motivation for school administrators. This internal encouragement is very much needed to implement Distance Learning during the covid-19 pandemic. Although faced with limited resources and distance of activities, with strong internal encouragement, the implementation of the educational function through Distance Learning activities in SMA Negeri can still meet the learning needs of students.

Second, the need for adaptation or internal encouragement of such individuals should be presented with the strength of a school environment that remains conducive to the development of a spirit of togetherness and cooperation between educational staff and students who help and strengthen each other with effective personal communication. With such strength, the motivation for education staff is strengthened in accordance with the demands and challenges of education during the COVID-19 pandemic, so that the performance of educational services in public high schools can still meet the learning needs of students.

Third, these abilities and strengths are then directed to achieve opportunities that enable or 
trigger the development of educational methods and media that are useful for improving the quality of educational services. The quality of education services is one of the factors supporting the implementation of an effective national education system. With these abilities, strengths and opportunities, various strategic steps have been taken to optimize the quality of education services that ensure the effectiveness of Distance Learning in State Senior High Schools.

Fourth, these abilities, strengths and opportunities are then developed into school culture values. The cultural values in question include beliefs, norms and school ethics in implementing various policies and teaching and learning activities in schools. These values are institutionalized to optimize the motivation of school administrators to create a Distance Learning Culture in State Senior High Schools.

Fifth, with abilities, strengths, opportunities and culture, various efforts were made to reorient schools to make SMA Negeri as an institution for the development of Agility (intelligence) of the young generation that can be relied upon to prepare future leaders of the nation. In time, these abilities, strengths, opportunities, culture and agility (ASOCA) need to be institutionalized as well as to optimize the implementation of the education function in schools in order to realize a modern, professional, national standard high school learning performance, and support the effectiveness of the implementation of the national education system to prepare future leaders of the nation who are honest, trustworthy and reliable in formulating and or implementing various policies to improve the quality of human resources through education.

From the descriptive analysis of various information obtained from research informants, and by using the ASOCA analysis approach, the practical implications of the need for innovation included in the Need For Achiement are obtained, which is one of the motivational dimensions of public high school administrators. The practical implications in question are as follows:

First, the need to innovate educational staff and students during the COVID-19 pandemic should be based on the ability to understand the threat of the COVID-19 pandemic and its impact on health, individuals, families and communities and their consequences on education. Thus, innovation becomes relevant and functional to overcome conditional constraints arising from the threat of the COVID-19 pandemic. In this context, the need to innovate education personnel and students certainly does not only motivate the implementation of health protocols; but at the same time also motivates the development of distance learning methods and media. This need to innovate, as an internal drive that is individual in nature, not only provides a strong motivation to survive during the COVID-19 pandemic; but at the same time provide a strong impetus to innovate and be creative. With the need to innovate that motivates him, education providers and students will certainly continue to strive to carry out the function of education with innovative methods and media. The need to innovate which is the internal drive of individuals and collective behavior is one of the motivational dimensions of school administration. This internal encouragement is very much needed to implement Distance Learning during the covid-19 pandemic. Although faced with limited resources and 
distance of activities, with a strong internal drive, the implementation of the educational function through Distance Learning activities in SMA Negeri can still meet the learning needs of students.

Second, the need to innovate or internal encouragement of such individuals should be presented with the strength of a school environment that remains conducive to the development of a spirit of togetherness and cooperation between educational staff and students. Togetherness and cooperation is carried out by helping and strengthening each other with effective personal communication. With such strength, it is also carried out to strengthen the motivation of educational staff in accordance with the demands and challenges of education during the COVID-19 pandemic, so that the performance of education services in public high schools can still meet the learning needs of students.ri that supports the implementation of an effective national education system.

Third, these abilities and strengths are then directed to achieve opportunities that enable or trigger the development of educational methods and media that are useful for improving the quality of educational services. The quality of education services is one of the factors supporting the implementation of an effective national education system. With these abilities, strengths and opportunities, various strategic steps have been taken to optimize the quality of education services that ensure the effectiveness of Distance Learning in State Senior High Schools.

Fourth, these abilities, strengths and opportunities are then developed into school culture values. The cultural values in question include beliefs, norms and school ethics in implementing various policies and teaching and learning activities in schools. These values are institutionalized to optimize the motivation for school administration in order to create a Distance Learning Culture in State High Schools that supports the implementation of an effective national education system during the COVID-19 pandemic.

Fifth, with abilities, strengths, opportunities and culture, various efforts were made to reorient schools to make SMA Negeri as an institution for the development of Agility (intelligence) of the young generation that can be relied upon to prepare future leaders of the nation. In time, these abilities, strengths, opportunities, culture and agility (ASOCA) need to be institutionalized as well as to optimize the implementation of the education function in schools in order to realize a modern, professional, national standard high school learning performance, and support the effectiveness of the implementation of the national education system to prepare future leaders of the nation who are honest, trustworthy and reliable in formulating and or implementing various policies to improve the quality of human resources through education.

From the descriptive analysis of various information obtained from research informants, and by using the ASOCA analysis approach, the practical implications of recreational needs included in Need For Achiement are one of the dimensions of motivation for state high school administrators. The practical implications in question are as follows:

First, the need for recreation, which is also defined as the creative need for educational staff 
and students during the COVID-19 pandemic, should be based on the ability to understand the threat of the COVID-19 pandemic and its impact on health, individuals, families and communities and their consequences on education. Thus recreation or creation becomes relevant and functional to overcome conditional constraints arising from the threat of the COVID-19 pandemic. In this context, the need for recreation or creation of education personnel and students certainly does not only motivate the application of health protocols; but at the same time it can also motivate the development of Distance Learning methods and media. This need for recreation and creation, as an internal drive that is individual and collective, not only provides a strong motivation to survive during the covid-19 pandemic; but at the same time provide a strong impetus for achievement. With the need for recreation and creation that motivates themselves, education providers and students will certainly continue to strive to carry out educational functions with creative methods and media. The need for recreation and creation which is the internal drive of individuals and collective behavior is one of the motivational dimensions of school administration. This internal encouragement is very much needed to implement Distance Learning during the covid-19 pandemic. Although faced with limited resources and distance of activities, with a strong internal drive, the implementation of the educational function through distance learning activities in public high schools can certainly meet the learning needs and expectations of students.

Second, the need for individual creativity or internal encouragement should be presented with the strength of a school environment that remains conducive to the development of a spirit of togetherness and cooperation between educational staff and students. Togetherness and cooperation are carried out by helping and strengthening each other by establishing effective personal communication. With such strength, it was also carried out to strengthen the motivation of educational staff in accordance with the demands and challenges of education during the COVID-19 pandemic. The aim is, among other things, to ensure that the performance of education services in public high schools can still meet the learning needs and expectations of students.

Third, these abilities and strengths are then directed to seize opportunities that enable or trigger the development of more effective educational methods and media to improve the quality of educational services. The quality of education services is one of the factors supporting the implementation of an effective national education system. With these abilities, strengths and opportunities, various strategic steps have been taken to optimize the quality of education services that ensure the effectiveness of Distance Learning in State Senior High Schools.

Fourth, these abilities, strengths and opportunities are then developed into school culture values. The cultural values in question include beliefs, norms and school ethics in implementing various policies and teaching and learning activities in schools. These values are institutionalized to optimize the motivation for school administration in order to create a Distance Learning Culture in State High Schools that supports the implementation of an effective national education system during the COVID-19 pandemic. 
Fifth, with abilities, strengths, opportunities and culture, various efforts were made to reorient schools to make SMA Negeri as an institution for the development of Agility (intelligence) of the young generation that can be relied upon to prepare future leaders of the nation. In time, these abilities, strengths, opportunities, culture and agility (ASOCA) need to be institutionalized as well as to optimize the implementation of the education function in schools in order to realize a modern, professional, national standard high school learning performance, and support the effectiveness of the implementation of the national education system to prepare future leaders of the nation who are honest, trustworthy and reliable in formulating and or implementing various policies to improve the quality of human resources through information technology-based teaching and learning activities.

From the descriptive analysis of various information obtained from research informants, and by using the ASOCA analysis approach, the practical implications of the need for achievement included in Need For Achiement are one of the dimensions of motivation for state high school administrators. The practical implications in question are as follows:

First, the fulfillment of the achievement needs of educational staff and students during the COVID-19 pandemic should be based on the ability to understand the threat of the COVID-19 pandemic and its impact on health, individuals, families and communities and their consequences on education. Thus the achievements made are relevant and functional to overcome the conditional constraints arising from the threat of the COVID-19 pandemic. In this context, the need for achievement of educational staff and students certainly does not only motivate the implementation of health protocols; but at the same time it can also motivate the development of Distance Learning methods and media. This need for achievement, as an internal drive that is both individual and collective, not only provides a strong motivation to survive during the covid-19 pandemic; but at the same time it also provides a strong impetus to achieve various achievements, especially non-academic achievements. With the need for achievement that motivates them, education providers and students will certainly continue to strive to carry out the function of education with innovative and creative methods and media. The need for achievement which is the internal drive of individuals and collective behavior is one of the motivational dimensions of school administration. This internal encouragement is very much needed to implement Distance Learning during the covid-19 pandemic. Although faced with limited resources and distance of activities, with a strong internal drive, the implementation of the educational function through Distance Learning activities in State Senior High Schools can of course still meet the learning needs and expectations of students to achieve certain achievements.

Second, the need for individual creativity or internal encouragement should be presented with the strength of a school environment that remains conducive to the development of a spirit of togetherness and cooperation between educational staff and students. Togetherness and cooperation are carried out by helping and strengthening each other by establishing effective personal communication. With such strength, it was also carried out to strengthen the motivation of educational staff in accordance with the demands and challenges of education during the COVID-19 pandemic. The goal is, among other things, that the performance of education services in public high schools can still meet the learning needs and expectations of 
students in achieving certain achievements.

Third, these abilities and strengths are then directed to achieve opportunities that allow or trigger certain achievements that indicate that the quality of education services is still being achieved. The quality of education services is one of the supporting factors for the implementation of an effective national education system. With these abilities, strengths and opportunities, various strategic steps were also taken to optimize the quality of educational services that ensure the effectiveness of Distance Learning in State Senior High Schools and achieve certain achievements.

Fourth, these abilities, strengths and opportunities are then developed into school culture values. The cultural values in question include beliefs, norms and school ethics in implementing various policies and teaching and learning activities in schools. These values should be institutionalized to optimize the motivation for school administration in order to create a Distance Learning Culture in State Senior High Schools that supports the implementation of an effective national education system during the COVID-19 pandemic with the achievement of various student achievements.

Fifth, with abilities, strengths, opportunities and culture, various efforts were made to reorient schools to make SMA Negeri as an institution for the development of Agility (intelligence) of the young generation that can be relied upon to prepare future leaders of the nation. In time, these abilities, strengths, opportunities, culture and agility (ASOCA) need to be institutionalized as well to optimize the implementation of the education function in schools in order to realize a modern, professional, national standard high school learning performance, and achieve international achievements in order to support the effectiveness of the system implementation. national education to prepare future leaders of the nation who are honest, trustworthy and reliable in formulating and or implementing various policies to improve the quality of human resources through information technology-based teaching and learning activities during the COVID-19 pandemic, which is not yet clear when it will end, but its impact so broad to the implementation of the national education system.

\subsection{New Concepts Developed From Discussion on the Effect of Organizational Culture, Competence and Motivation on the Quality of Educational Services}

Definition: The new concept is the result of the development of driven theory in the construction of research variables. The New Concept is compiled based on the Conceptual Basis which is arranged according to the driven theory and the Factual Basis which is arranged according to the results of the Second CFA.

4.3.1 The New Concept which is composed of a discussion of the influence of Organizational Culture on the Quality of Education Services at State Senior High Schools in West Java Province is a new concept of School Organizational Patterns with the following conceptual structure:

Definition of the New Concept: School Organizational Patterns are the office structure and work procedures of the organizers and implementation of education in schools which are stated by the distribution of authority, the pattern of division of tasks and job descriptions. 
From the definition of this new concept, three dimensions are formed: (1) Dimensions of the Distribution of Authority for the Implementation of Education in Schools, (2) Dimensions of the Pattern of Distribution of Tasks for School Organizers, and (3) Dimensions of Job Descriptions for School Organizers and Administration.

Description of the New Concept: The three-dimensional description of the School Organizational Pattern is as follows:

\section{Distribution of School Administration Authority}

Distribution of School Administration Authority which is institutionalized into the cultural values of school organizations is a pattern of distribution of authority among school administrators according to the duties and functions of administering the education system in schools. The implementation of the distribution of authority for school administrators is stated by a description of the duties and functions of structural and functional positions which are structured into a school organizational pattern. The structural positions in question consist of the Principal, Deputy Principal, Head of Administration, staff, and school administrators. While functional positions consist of teachers and trainers/instructors. In addition, there is a School Committee which has certain authorities and becomes school partners. In order for the distribution of authority to be evenly distributed with a clear scope of work for each position, the Principal should be positioned as Top Manager and at the same time Top Leader; The Deputy Principal is positioned as the School Manager, and the Head of Administration is seen as the Chief of Staff who oversees a number of staff. In order to make teaching and learning authority clearer, the number of teachers and the number of subjects should be balanced; and it may be that a teacher concurrently holds more than one subject; but it would be better if the principles of specialization and professionalization were put forward. Especially for extracurricular teachers, each school extracurricular activity should be entrusted to a teacher, trainer, or instructor. With such a pattern of distribution of authority, public schools, which are positioned as the Technical Implementation Unit of the Education Office (UPTD), are at the forefront of the implementation of the national education system. In order for the implementation of the national education system in public schools to be more effective, the functionalization and optimization of public schools as the spearhead of formal education should be freed from all unnecessary structural interventions. The provisions are clear that state schools are UPTD. So, all technical education policies should be left entirely to schools based on the implementation of education decentralization and school autonomy policies. Later than that, School-Based Management was also developed by optimizing the role of the Principal as the top manager and at the same time the top leader, and the Deputy Principal as the school manager. Thus the authority of the Principal and Deputy Principal becomes clear and real. In this context, the distribution of the Principal's authority to the Deputy Principal as well as to staff and teachers is one of the factors that affect the effectiveness of the implementation of technical learning policies in schools. Meanwhile, the authority of the Principal as the top manager and at the same time the top leader is one element of the embodiment of the school's organizational culture which is institutionalized into an organizational structure. 


\section{The pattern of Division of Tasks of School Administrators}

The pattern of division of tasks that is institutionalized into the cultural values of the school organization is the work order among school administrators according to the school's organizational structure. This division of tasks is formed from the concept of organizing schools as the spearhead of the implementation of the national education system that deals directly with students. The division of tasks in this school is formed from the application of the basic pattern of teaching and the implementation of the function of education in schools. Thus, in general, the division of tasks in this school can be stated as a process of actualizing beliefs, norms and behavior of school organizations in carrying out educational functions. In particular, the division of tasks in this school is the implementation of the school's organizing function that forms a series of school organizational behaviors in implementing various policies, programs and educational activities in schools. In a broader context, the division of tasks in schools is also related to the implementation of the duties and functions of other agencies and institutions that are coordinated in the implementation of the education system in schools. Meanwhile, the implementation of the division of tasks in schools is not only influenced by the management of school administrative resources but is also influenced by the implementation of a school-based management system. Therefore, transparent, effective, efficient and accountable management of school administrative resources as well as the implementation of school-based management functions in a professional manner are very important in enforcing job descriptions. For this reason, communicative and accommodative leadership behavior of the Principal is also needed in order to optimize the management of school administrative resources and at the same time streamline the implementation of school-based management functions. Then rather than that, dynamically the division of tasks shapes the performance of school administrators and school performance. The division of tasks that are internalized into the cultural values of this school organization situationally and conditionally clearly affect the quality of educational services.

\section{Job Description of School Organizers and Organizers}

The description of the duties of the organizers and the organization of schools that are institutionalized into the cultural values of the school organization is a job description for each position or position of school administrators according to the school's organizational structure. This job description is formed from the concept of organizing schools as the spearhead of the implementation of the national education system that deals directly with students. The job description in this school refers to the efficient use of school administrative resources for the implementation of the educational function in schools. Thus, in general, the job description in this school can be stated as a process of actualizing beliefs, norms and behavior of school organizations in implementing various policies, programs and educational activities in schools. In particular, the job description in this school is formed from the implementation of the school organizing function and is actualized into a series of school organizational behaviors in carrying out teaching and learning activities (Suradinata, 1996). In a broader context, the job description in this school is also related to the implementation of the duties and functions of other agencies and institutions that are coordinated in the implementation of the national education system. Meanwhile, the implementation of the job 
description function in this school is not only influenced by the management of school administrative resources but is also influenced by the implementation of a school-based management system (Ghozali, 2008). Therefore, transparent, effective, efficient and accountable management of school administrative resources as well as the implementation of school-based management functions in a professional manner are very important in enforcing job descriptions. For this reason, communicative and accommodative leadership behavior of the Principal is also needed in order to optimize the management of school administrative resources and at the same time streamline the implementation of school-based management functions. Then rather than that, dynamically job descriptions shape the performance of school administrators and school performance. The job description which is internalized into the cultural values of this school organization situationally and conditionally clearly affects the quality of educational services.

4.3.2 The New Concept which is composed of a discussion of the influence of Competence on the Quality of Education Services at State Senior High Schools in West Java Province is a new concept on the Characteristics of the Response of Education Providers with the following conceptual structure:

Definition of the New Concept: Characteristics of Response of Education Providers is the consistency of attitudes and actions of education providers in schools in dealing with situations and conditions that require certain adjustments which are revealed from adaptive attitudes and actions, responsive attitudes and actions, cooperative attitudes and actions. From the definition of this new concept, three dimensions of response characteristics of education providers are formed: (1) Dimensions of Attitudes and Adaptive Actions of Education Providers, (2) Responsive Attitudes and Actions of Education Providers and (3) Cooperative Attitudes and Actions of Education Providers.

Description of the New Concept: Three-dimensional descriptions of the characteristics of the response of school administrators are as follows:

\section{Adaptive Attitudes and Actions of Education Providers}

The adaptive attitude and action of education providers in schools is the ability to adapt individuals in the face of changes in the educational environment in accordance with their field of duties and responsibilities. These adaptive attitudes and actions arise because of the growing personal awareness that the ability to adapt and do the right and right things in certain situations and conditions is a process of self-actualization. Such adaptive attitudes and actions are the embodiment of changes in views, attitudes and behavior that are in line with the demands and challenges arising from changes in the educational environment. Thus, a person or group of people can be declared capable of effectively actualizing adaptive attitudes and actions if that person or group of people is able to deal with changes in the educational environment professionally and proportionally in accordance with their duties and responsibilities. This adaptive attitude and action can be said to be one of the elements of the competence of education personnel that is correlated with educational performance in schools. These adaptive attitudes and actions certainly do not escape the internal impulses that directly or indirectly affect the psychological needs, social needs and economic needs of individuals. 
In addition, the dynamic conditions of the school environment can also be correlated with the strong or weak attitudes and adaptive actions of education personnel. Therefore, in certain situations and conditions that require total self-adjustment, such as the demands of the COVID-19 pandemic, the adaptive attitude and action of education providers is very important. The attitude and adaptive actions of education providers in this school are revealed, among others, from the performance of Distance Learning.

\section{Responsive Attitudes and Actions of Education Providers}

Responsive attitudes and actions of education providers are individual responsiveness in responding to developments, needs and problems arising from changes in the educational environment in accordance with their field of duties and responsibilities. Responsive attitudes and actions that are formed from sensitivity and appropriate and correct actions to certain situations and conditions are a process of self-actualization. Such responsive attitudes and actions are the embodiment of views, attitudes and behaviors that are aligned with the demands and challenges arising from changes in the educational environment. Thus, a person or group of people deserves to be considered capable of actualizing responsive attitudes and actions effectively if that person or group of people is able to deal with changes in the educational environment in a professional and proportional manner. Professional in the sense that these abilities are demonstrated with optimal professionalism and professionalism. Proportional in terms of the ability is shown in accordance with the field of duties and responsibilities. This responsive attitude and action is formed from a person's certain awareness and sensitivity to the dynamics of development, needs and educational problems in schools. Thus, a person or group of people who work in schools deserves to be considered capable of showing responsive attitudes and actions effectively if they have certain competencies, awareness and sensitivity to deal with changes in the educational environment. Such responsive attitudes and actions are one element of individual competence that correlates with individual performance in implementing policies and educational service activities in schools. This responsive attitude and action certainly does not escape from internal impulses that are directly or indirectly correlated with psychological needs, social needs and individual economic needs. In addition, the dynamic conditions of the school environment can also be strongly correlated with the strength or weakness of individual responsive attitudes and actions. Consciously or unconsciously by each individual, these responsive attitudes and actions are revealed to be work views, work attitudes and individual work behaviors in carrying out educational functions in schools. Therefore, in certain situations and conditions that require sensitivity and certain actions in total, such as demands during the COVID-19 pandemic, the responsive attitude and action of education providers is very important. The responsive attitude and actions of these education providers are revealed, among others, from the compliance with health protocols.

\section{Attitudes and Cooperative Actions of Education Providers}

The cooperative attitude and action in question is the consistency of a person in cooperating in the implementation of work or activities that must be carried out by working together; and or hand over to others. A person's consistency in establishing this collaboration can arise 
because of a personal awareness that there are many things that cannot be done alone. There is a lot of work to be done with other people; and or even handed over to other people who are experts. A person's consistency in cooperating can be consistent or inconsistent, depending on the views and attitudes of a person in interpreting and assessing his work. In addition, a person's consistency in cooperating could be due to his calculation of the advantages or disadvantages of his work; and be aware of strengths or weaknesses in carrying out the work. Thus, a person who is on duty at a school can be declared to have a person's consistency in establishing optimal cooperation if there is an awareness within him that there are many things that cannot be done alone; and or must cooperate. One's consistency in establishing this collaboration is one element of individual competence that is positively correlated with individual performance in implementing policies and educational service activities in schools. The consistency of a person in establishing this collaboration certainly does not escape from internal encouragement which is directly or indirectly positively correlated with psychological needs, social needs and individual economic needs. In addition, the dynamic conditions of the school environment can also be positively correlated with a person's strong or weak consistency in cooperating. Consciously or unconsciously, a person's consistency in collaborating is also revealed to be a work view, work attitude and work behavior; and judged by the people they work with. Therefore, the consistency of a person in establishing cooperation is one of the factors that affect the position, role and responsibility of that person. A person's consistency in cooperating which is actualized into a work view, work attitude and individual work behavior affects the implementation of the educational function in schools. Therefore, in certain situations and conditions that require total consistency of cooperation, such as cooperation in responding to, overcoming and at the same time anticipating the impact of the COVID-19 pandemic, the consistency of cooperation in education providers is very important. The consistency of cooperation between education providers is revealed, among others, from distance learning activities and compliance with health protocols.

4.3.3 The New Concept which is composed of a discussion of the influence of Motivation on the Quality of Education Services at State Senior High Schools in West Java Province is a new concept regarding the Characteristics of the Response of Education Providers with the following conceptual structure:

Definition of the New Concept: Achievement Drive is an internal drive and/or individual need to achieve something through work or activities that is revealed from the process of fulfilling the need for adaptation, the need for innovation, the need for creativity, and the need for achievement. From the definition of this new concept, four dimensions of needs are formed which include: (1) Adaptation Needs, (2) Innovation Needs, (3) Creative Needs, and (4) Achievement Needs.

Description of the New Concept: The description of the four dimensions of Achievement Drive is as follows:

\section{Adaptation Needs}

The need for adaptation in question is the desire or internal drive of a person or group of 
people for the importance of adjusting individual views, attitudes and behavior in line with the dynamics of changes in the strategic educational environment, especially changes that occur in the school environment as a result of the COVID-19 pandemic. This need for adaptation arises when there is individual awareness or collective awareness to do various important things that are deemed necessary to respond to, overcome and at the same time anticipate changes in the educational environment that arise from the rapid development of society and the progress of science and technology which is increasingly globalized. For example, the rapid advancement of educational information technology which is applied to various learning practices and technical teaching requires every individual to master the educational information technology. Meanwhile, the dynamic development of society shows a change in orientation and lifestyle that is increasingly individual and materialistic. This change is certainly not only faced by education providers but also faced by students. The application of the distance learning pattern is a technical change in education that not only requires education providers to provide and master educational information technology; but also requires students to be able to master the educational information technology. In addition, changes in educational policies, changes in learning curricula and adjustments to teaching methodologies are also demands and challenges for all elements of the implementation of the education system in schools. Therefore, the need to adapt appears to be a professional need and at the same time a conditional need for every education provider; and also become a technical requirement for students in participating in teaching and learning activities at school. In this context, the need to adapt will not only encourage the adjustment of educational behavior; but at the same time it will also encourage creative learning behavior in schools. Thus, it can be stated that basically every person or group of people has the need to adapt; but not every person or not all groups of people can do and or meet the need to adapt. Why is that, because not every person and or group of people has the need to adapt. This is due to the mental attitude of a person or group of people who are anti-change or indeed unable to adapt. Especially if the change disturbs the comfort or stability of a person or group of people. In addition, there are limited resources to perform or meet the need to adapt is also an obstacle. The resources in question can come from individual factors such as intellectual weakness, social limitations and financial absence. The resources in question can also be sourced from institutional factors such as limited human resources (man), limited budget resources (man), limited resources for infrastructure (materials), limited technological resources (machines), and limited public resources. (markets). Meanwhile, despite being faced with limited resources, the need to adapt as a desire or hope, consciously or unconsciously, the need to adapt is still one of the factors that affect the performance of a person or group of people in implementing policies and educational service activities in schools.

\section{Need to Innovate}

The need for innovation in question is the desire or internal drive of a person or group of people for the importance of innovation or a practical finding that can be used as a solution and or anticipation of the impact of changes in the strategic environment of education, especially changes that occur in the school environment as a result of the COVID-19 pandemic. This need to innovate arises when there is individual awareness or collective 
awareness to do various things that are deemed necessary to address, overcome and at the same time anticipate various practical obstacles and situational obstacles in the educational environment that arise from the rapid development of society and the progress of science and technology which is increasingly globalized. For example, the rapid advancement of educational information technology which is applied to various learning practices and technical teaching requires every individual to master the educational information technology. Meanwhile, changes to the lesson curriculum and adjustments to learning methods that occurred as a result of the COVID-19 pandemic increasingly encouraged innovative efforts. This change is certainly not only faced by education providers but also faced by students. The application of distance learning patterns is a technical change in education that not only requires education providers to master educational information technology as well as changes to curriculum and teaching methods; but also requires students to be able to master information technology in learning practice. In addition, changes in educational policies, changes in learning curricula and adjustments to teaching methodologies have also become its own demands and challenges for all elements of the implementation of the education system in schools. Therefore, the need to innovate appears to be a professional need and at the same time a conditional need for every education provider; and also become a technical requirement for students in participating in teaching and learning activities. In this context, the need to innovate will not only encourage educational innovation; but at the same time it will also encourage innovative behavior in education in schools. Thus, it can be stated that basically every person or group of people has the need to innovate; but not every person or not all groups of people can do and or fulfill the need to innovate. Why is that, because not every person and or group of people has the need to innovate. This is due to the mental attitude of a person or group of people who are not able to get an innovation, even in the simplest terms. Moreover, if the innovation process requires financing with a certain amount that is considered burdensome, then automatically the fulfillment of the need for innovation becomes weak, and ultimately non-existent. Meanwhile, despite being faced with limited resources and intentional laziness, the need to innovate as an internal desire or drive, consciously or unconsciously, this need to innovate remains one of the factors that affect the performance of a person or group of people in implementing policies and educational service activities. in school. The need for innovation in question is the desire or internal drive of a person or group of people to create and/or change something in order to overcome stagnation, boredom and doubt about doing something as a result of changes in the educational environment, especially changes that occur in the school environment as a result of the COVID-19 pandemic. This creative need can arise when there is individual awareness or collective awareness to do various important things that are deemed necessary to address, overcome and at the same time anticipate stagnation, boredom and doubt in carrying out the learning process at school. For example, the prohibition of holding face-to-face learning caused almost all subject matter, teaching methods and learning media to change; and even partially eliminated. The logical consequences include learning situations and conditions that are less pleasant; and even create new problems that may be difficult for students to overcome. For example, limited learning facilities and weak motivation to learn. The situation of stagnation, boredom and doubt in carrying out the learning process in this school 
is certainly not only felt by education providers; but also felt by students. It turns out that the practice of Distance Learning does not only bring about technical changes in learning that not only requires adjustment of teaching and learning attitudes and behavior; but also requires an adjustment of mental attitude to these changes. In addition, changes in education policies, changes in learning curricula and adjustments in teaching methodologies are also demands and challenges for all elements of the implementation of the education system in schools. Therefore, the need to innovate seems to be an intellectual need as well as an emotional need for education providers. In this context, the need to innovate will not only encourage creativity in teaching and learning in the classroom; but at the same time it will also encourage creative learning behavior in schools. Thus, it can be stated that basically every person or group of people has the need to innovate; but not every person or not all groups of people can perform and or meet the need to innovate. Why is that, because not every person and or group of people has a strong need to innovate. This is due to the mental attitude of a person or group of people who are "accepting as they are" for something that happened as a result of the unclear end of the COVID-19 pandemic. In addition, the limited resources to achieve an innovation or meet the need to innovate is also an obstacle. The resources in question can come from individual factors such as intellectual weakness, social limitations and financial absence. The resources in question can also be sourced from institutional factors such as limited educational resources in schools. Meanwhile, despite being faced with limited resources, the need to innovate as an internal desire or drive, consciously or unconsciously becomes one of the factors that affect the performance of a person or group of people in implementing policies and educational service activities in schools.

\section{Creative Needs}

The need for creativity is the desire or internal drive of a person or group of people to create and/or change something in order to overcome stagnation, boredom and doubt in doing something as a result of changes in the educational environment, especially changes that occur in the school environment as a result of the COVID-19 pandemic This creative need can arise when there is individual awareness or collective awareness to do various important things that are deemed necessary to address, overcome and at the same time anticipate stagnation, boredom and doubt in carrying out the learning process at school. For example, the prohibition of holding face-to-face learning caused almost all subject matter, teaching methods and learning media to change; and even partially eliminated. The logical consequences include learning situations and conditions that are less pleasant; and even create new problems that may be difficult for students to overcome. For example, limited learning facilities and weak motivation to learn. The situation of stagnation, boredom and doubt in carrying out the learning process in this school is certainly not only felt by education providers; but also felt by students. It turns out that the practice of Distance Learning does not only bring about technical changes in learning that not only requires adjustment of teaching and learning attitudes and behavior; but also requires an adjustment of mental attitude to these changes. In addition, changes in education policies, changes in learning curricula and adjustments in teaching methodologies are also demands and challenges for all elements of the implementation of the education system in schools. Therefore, the need for 
creativity appears to be an intellectual need as well as an emotional need for education providers. In this context, the need for creativity will not only encourage teaching and learning creativity in the classroom; but at the same time it will also encourage creative learning behavior in schools. Thus, it can be stated that basically every person or group of people has a creative need; but not every person or not all groups of people can do and or fulfill creative needs. Why is that, because not every person and or group of people has a strong creative need. This is due to the mental attitude of a person or group of people who are "accepting as they are" for something that happened as a result of the unclear end of the COVID-19 pandemic. In addition, there are limited resources to create creations or fulfill creative needs is also an obstacle. The resources in question can come from individual factors such as intellectual weakness, social limitations and financial absence. The resources in question can also be sourced from institutional factors such as limited educational resources in schools. Meanwhile, despite being faced with limited resources, the need for creativity as an internal desire or encouragement, consciously or unconsciously becomes one of the factors that affect the performance of a person or group of people in implementing policies and educational service activities in schools.

\section{Achievement Needs}

The need for achievement in question is the desire or internal drive of a person or group of people to achieve certain achievements or a success from the implementation of their work or activities. This need for achievement arises when an individual or group of individuals has an awareness of the importance of achievement or success that gives a sense of satisfaction or can be proud of, and or provides benefits to others. This need for achievement stems from certain competencies and ambitions possessed by an individual (individual achievement) or a group of individuals (collective achievement); related to learning performance in schools. For example, a teacher or group of teachers can teach a group of students effectively; by showing optimal learning achievement; and become the pride of the school. Thus, the need for achievement is revealed to be the need for self-actualization of professional education providers; and also becomes the need for self-actualization of students in participating in teaching and learning activities at school. In this context, fulfilling the need for achievement does not only increase the effectiveness of the implementation of the educational function; but at the same time increasing the professionalism and professionalism of learning in schools. Therefore, it can be stated that basically every person or group of people has a need for achievement; but not every person or not all groups of people can perform and or fulfill the need for achievement, because achievement is a manifestation of the competence and professional ambition of a person or group of people. The achievements in question can be in the form of innovative works or can also be in the form of creative works. Meanwhile, despite being faced with limited resources, the need for achievement - as a desire or internal drive of an individual or group of individuals - consciously or unconsciously fulfilling the need for achievement is one of the factors that affect the performance of a person or group of people in implementing policies and educational service activities. in school. 


\section{Closing}

The conclusions obtained from the discussion of the research results are as follows:

First, the magnitude of the influence of Organizational Culture on the Quality of Education Services at State Senior High Schools in West Java Province reached 0.69, which is quite strong and significant. The magnitude of the influence of Organizational Culture on the Quality of Education Services at the State Senior High School is determined by 12 manifest variables. The existence of such an influence shows that between the Organizational Culture of Public Senior High Schools and the Quality of Educational Services there is a meaningful causal relationship: if the Organizational Culture of State Senior High Schools is improved or increased, stimulantly the increase in Organizational Culture is followed by an increase in the Quality of Education Services.

Second, the magnitude of the influence of competence on the quality of education services at public high schools in West Java province reaches 0.55 , which is quite strong and significant. The magnitude of the influence of competence on the quality of education services at the public high schools is determined by 15 manifest variables. The existence of such an influence indicates that there is a causal relationship between the Competence of Public Senior High School Providers and Quality of Education Services, a significant causal relationship exists: if the Competence of Public Senior High School Operators is increased or increased, the stimulant increase in Competence is followed by an increase in the Quality of Education Services.

Third, the magnitude of the influence of motivation on the quality of education services at public high schools in West Java province reached 0.86, which is very strong and significant. The magnitude of the influence of motivation on the quality of education services in SMA Negeri is determined by 12 manifest variables. The existence of such an influence shows that there is a causal relationship between the motivation of public high school administrators and the quality of education services: if the motivation of public high school administrators is increased or increased, then stimulantly the increase in motivation is followed by an increase in the quality of education services.

Fourth, the new concept that can be compiled from the discussion of the results of research on the influence of Organizational Culture on the Quality of Education Services at State Senior High Schools in West Java Province is a new concept of School Organizational Patterns with the definition: School Organizational Patterns are the administration and work procedures of the organizers and implementation of education in schools. which is expressed by the distribution of authority, the pattern of division of tasks and job descriptions. From the definition of this new concept, three dimensions are formed: (1) Dimensions of the Distribution of Authority for the Implementation of Education in Schools, (2) Dimensions of the Pattern of Distribution of Tasks for School Organizers, and (3) Dimensions of Job Descriptions for School Organizers and Administration.

Fifth, a new concept that can be compiled from the discussion of the results of research on the influence of competence on the quality of education services at public high schools in West Java Province is a new concept about the characteristics of the response of education providers with the definition: Characteristics of the response of education providers is the 
consistency of attitudes and actions of education providers in schools in facing situations and conditions that require certain adjustments that are revealed from adaptive attitudes and actions, responsive attitudes and actions, cooperative attitudes and actions. From the definition of this new concept, three dimensions of response characteristics of education providers are formed: (1) Dimensions of Attitudes and Adaptive Actions of Education Providers, (2) Responsive Attitudes and Actions of Education Providers and (3) Cooperative Attitudes and Actions of Education Providers.

Sixth, a new concept that can be compiled from the discussion of the results of research on the influence of motivation on the quality of education services at public high schools in West Java Province is a new concept of achievement encouragement with the definition: achievement drive is an internal drive and or individual need to achieve something through work or activities that revealed from the process of fulfilling the need for adaptation, the need for innovation, the need for creativity, and the need for achievement. From the definition of this new concept, four dimensions of needs are formed which include: (1) Adaptation Needs, (2) Innovation Needs, (3) Creative Needs, and (4) Achievement Needs.

\section{Reference}

Arif, A., \& Maksum, I. R. (2017). Functional decentralization Construct in Decentralization Policy in Indonesia (A study of Irrigation, Education, and Free trade sectors). JKAP (Jurnal Kebijakan Dan Administrasi Publik). https://doi.org/10.22146/jkap.25383

Boyne, G. A., Gould-Williams, J. S., Law, J., \& Walker, R. M. (2004). Toward the self-evaluating organization? An empirical test of the wildavsky model. Public Administration Review, 64(4), 463-473. https://doi.org/10.1111/j.1540-6210.2004.00392.x

Bradley, R. C. (1997). "Citizens and Governance": An Alternative Approach to American Government. PS: Political Science and Politics, 30(3), 553-557. http://search.ebscohost.com/login.aspx?direct=true \&db=eric \&AN=EJ557637\&site=ehost-liv e

D.J creswell. (2009). John_W._Creswell_Research_Design_Book.pdf. https://books.google.co.za/books?hl=en\&lr=lang_en\&id=EbogAQAAQBAJ\&oi=fnd\&pg=P R1\&dq=quantitative+creswell\&ots=cahMpXRAF8\&sig=jN66MOd3r5nCuoPAbLJry9QwdQ $\mathrm{Q} \# \mathrm{v}=$ onepage $\& \mathrm{q}=\mathrm{quantitative}$ creswell $\& \mathrm{f}=$ false

Ghozali, I. (2004). Model Persamaan Structural Konsep dan Aplikasi dengan Program AMOS Versi 5.0. Universitas Diponegoro Press.

Ghozali, I. (2008). Structural Equation Modeling Metode Alternatif dengan Partial Least Square (PLS) (2nd ed.). Universitas Diponegoro Press.

Kerlinger, F. N. (2006). Asas-Asas Penelitian Behavioral (L. R. Simatupang (ed.); 3rd ed.). Gadjah Mada University Press.

Neumann, L. E. (2006). Basics of Social Research Qualitative and Quantitative Approaches. In Pearson inc. (2nd Editio). Pearson Inc.

Santoso, S. (2007). Structural Equation Modeling. PT. Elex Media Komutindo. 
Sheng, H. H. (2006). Robustness Testing of PLS, LISREL,EQS and ANN-based SEM for Measuring Customer Satisfaction. Total Quality Management, 17(3), 355-371.

Suradinata, E. (1996). Manajemen Sumber Daya Manusia. CV. Ramadhan.

Suradinata, E. (2013a). Analisis Kepemimpinan, Strategi Pengambilan Keputusan. Alqaprint.

Suradinata, E. (2013b). How to Build a Nation, Reformasi dan Administrasi Pemerintahan. Lembaga Ketahanan Nasional Republik Indonesia.

Thoha, M. (2006). Perilaku Organisasi, Konsep Dasar dan Aplikasinya. PT. Raja Grafindo Persada.

Yun, E. G. (2006). Administrative system and culture in East Asia, Europe and the USA: A transformation of the administrative system through the mutual mixture of cultures in Korea. International Review of Administrative Sciences, 72(4), 493-516. https://doi.org/10.1177/0020852306070080

Zeithaml, V., Parasuraman, A., \& Leonard A. Berry. (1990). Delivering Quality Service: Balancing Customer Perception and Expectation. The Free Press Advision of Mac Millan Inc.APHY.

\section{Copyright Disclaimer}

Copyright for this article is retained by the author(s), with first publication rights granted to the journal.

This is an open-access article distributed under the terms and conditions of the Creative Commons Attribution license (http://creativecommons.org/licenses/by/4.0/). 